\title{
AVALIAÇÃO SOBRE A REDUÇÃO DA ATIVIDADE MICROBIANA NA ADUBAÇÃO ORGÂNICA E SUA INFLUÊNCIA NO CRESCIMENTO DO MILHO E RESPIRAÇÃO DO SOLO
}

Bruna Coelho de Lima, Fabio Fernando de Araujo

Universidade do Oeste Paulista - UNOESTE, Agronomia, Presidente Prudente, SP. E-mail: brunacoelhoo@outlook.com

\section{RESUMO}

O objetivo do presente trabalho foi avaliar o efeito da incorporação de matéria orgânica natural e matéria orgânica irradiada ao solo, sobre o crescimento do milho e respiração do solo. 0 experimento foi conduzido em casa de vegetação e laboratório de microbiologia. Para a adubação orgânica foi utilizado esterco bovino curtido retirado da fazenda de produção de leite. Para redução da atividade microbiana no esterco utilizou-se a técnica da irradiação utilizando-se o forno micro-ondas. O delineamento experimental empregado foi de blocos inteiramente casualizados contendo cinco tratamentos, com e sem irradiação e quatro repetições. Com 65 dias após a semeadura, foram feitas as avaliações da altura e massa seca de plantas. Foi também realizada a coleta de amostras de solo para a avaliação da atividade microbiana pelo método da respiração basal do solo. A aplicação do esterco natural favoreceu a maior atividade microbiana no solo quando comparada a mesma matéria orgânica irradiada. O esterco natural promoveu o maior crescimento do milho indicando doses próximas de dez toneladas por hectare com ajuste quadrático significativo $(p<0,05)$ o que não ocorreu no uso do esterco irradiado que proporcionou ajuste linear.

Palavras-chave: crescimento de planta; esterco bovino; microrganismos; respiração do solo.

\section{EVALUATION ON THE REDUCTION OF MICROBIAL ACTIVITY IN ORGANIC FERTILIZATION AND ITS INFLUENCE ON MAIZE GROWTH AND SOIL RESPIRATION}

\begin{abstract}
The objective of the present work was to evaluate the effect of the incorporation of organic matter and organic matter irradiated to the soil, on corn growth and soil respiration. The experiment was conducted in a greenhouse and microbiology laboratory. For organic fertilization, bovine manure was taken from the dairy farm. To reduce microbial activity in manure, the irradiation technique was used using the microwave oven. The experimental design was a completely randomized block containing five treatments, with and without irradiation and four replications. At 65 days after sowing, height and dry mass evaluations of plants were made. Soil samples were also collected for the evaluation of microbial activity by basal soil respiration method. The application of natural manure favored the greater microbial activity in the soil when compared to the same organic matter irradiated. Natural manure promoted the highest growth of maize indicating doses close to ten tons per hectare with a significant quadratic adjustment $(p$ $<0.05)$, which did not occur in the use of irradiated manure that provided linear adjustment.
\end{abstract}

Key words: plant growth; bovine manure; microorganisms; soil respiration. 


\section{INTRODUÇÃO}

Os excrementos dos animais foram muito utilizados no passado, mas com o surgimento dos adubos químicos, o interesse por fertilizantes orgânicos reduziu (SILVA et al., 2004). Hoje, o cuidado em relação à degradação ambiental relembrou o interesse pelo uso dos estercos, em especial, pela procura de uma agricultura sustentável (BRUMMER, 1998).

A utilização de insumos orgânicos ao solo tem como benefícios, melhorias físicas, como aumento da porosidade, maior aeração e retenção de água, facilitando o crescimento das plantas (TEJADA et al., 2016); químicas, melhorando a fertilidade do solo; e biológicas, aumentando a população e diversidade dos microrganismos que nele habitam (MARROCOS et al., 2012).

A qualidade edáfica pode ser compreendida a partir de alterações em suas características. Para isso, devem ser escolhidos indicadores os quais são substitutos calculáveis dos atributos do solo (PRAGANA et al., 2012) que possibilitam identificar, acompanhar e avaliar as modificações ocorridas num determinado ecossistema (ARAÚJO et al., 2013). Entre os indicadores de qualidade do solo, os biológicos ou bioindicadores requerem atenção especial, pois os microrganismos são responsáveis por vários processos e funções, como a decomposição de resíduos, ciclagem de nutrientes, composição de substancias húmicas, e associação de partículas do solo (BURNS et al., 2013).

A produção agrícola necessita do processo de decomposição do material orgânico no solo e da resultante mineralização dos nutrientes. Nesse sentido, a biomassa microbiana do solo, atua como importante estoque de nutrientes essenciais às plantas (GRISI; GRAY, 1986).

Várias categorias de adubos orgânicos possuem a capacidade de elevar 0 rendimento dos grãos de milho, entre eles, esterco bovino (MENESES, 1993), esterco de suínos ou cama de aves (ERNANI, 1984).
Doan et al. 2015, obtiveram valores elevados de massa seca de milho quando cultivados com adubo orgânico em relação ao cultivo com adubo mineral. A produtividade de grãos no país é muitas vezes restringida pelo custo elevado dos insumos, sendo o fertilizante o mais caro, atuando na ordem de 23 a $27 \%$ no custo total de produção (CASTRO; REIS; LIMA, 2006). Goulart et al 2015, concluíram que o adubo orgânico pode substituir o mineral mantendo a produtividade do milho e com redução de custo na adubação

Diante disso, o objetivo do trabalho foi avaliar o efeito da incorporação de matéria orgânica natural e irradiada por micro-ondas ao solo, sobre o crescimento do milho e respiração do solo.

\section{MATERIAL E MÉTODOS}

O experimento foi conduzido na Universidade do Oeste Paulista (UNOESTE), em casa de vegetação e as avaliações no laboratório de Biologia do Solo. Para isto, inicialmente foram coletadas amostras de solo em área de cultivo agrícola com predomínio de solos arenosos (argissolo), nas seguintes coordenadas geográficas: $22^{\circ} 7^{\prime} 39^{\prime \prime} \mathrm{S}$; $51^{\circ} 23^{\prime} 8^{\prime \prime} \mathrm{W}$, as quais foram coletadas na profundidade de $0-20 \mathrm{~cm}$. As amostras foram homogeneizadas e colocadas em vasos com capacidade de $8 \mathrm{~kg}$. A análise prévia de fertilidade do solo apresentou os seguintes resultados: $\mathrm{pH}$ Cloreto de Cálcio $\left(\mathrm{CaCl}_{2}\right)=5.2$; Alumínio $\mathrm{Al}\left(\mathrm{mmol}_{\mathrm{c}} \mathrm{dm}^{-3}\right)=0$; Matéria orgânica $\left(\mathrm{g} \mathrm{dm}^{-3}\right)=11$; Fósforo $P(\mathrm{mg}$ $\left.\mathrm{dm}^{-3}\right)=18$; Potássio $\mathrm{K}\left(\mathrm{mmol}_{\mathrm{c}} \mathrm{dm}^{-3}\right)=0,4$; Cálcio Ca $\left(\mathrm{mmol}_{\mathrm{c}} \mathrm{dm}^{-3}\right)=7$; e Soma de bases $(\%)=43$.

Para a adubação orgânica foi utilizado esterco bovino retirado de baia de confinamento leiteiro. Para a redução da atividade microbiana no esterco, empregouse a técnica de irradiação (FERREIRA et al. 1999), utilizando-se o forno micro-ondas, marca Brastemp, potência 1,4 KW. O esterco foi irradiado pelo tempo de 10 minutos. O delineamento experimental aplicado foi o de blocos inteiramente casualizados contendo 
cinco tratamentos, esterco irradiado e sem irradiação, compostos por quatro repetições. Para a condução do experimento foram estabelecidas as dosagens, sendo: T0: testemunha sem esterco; T1: $20 \mathrm{~g}$ de esterco natural por vaso $\left(5,0 \mathrm{Mg} \mathrm{ha}^{-1}\right) ; \mathrm{T} 2: 40 \mathrm{~g}$ de esterco natural por vaso $\left(10,0 \mathrm{Mg} \mathrm{ha}{ }^{-1}\right)$; T3: $60 \mathrm{~g}$ de esterco natural por vaso $\left(15,0 \mathrm{Mg}\right.$ ha ${ }^{-}$ $\left.{ }^{1}\right)$; T4 $80 \mathrm{~g}$ de esterco natural por vaso $(20,0$ $\left.\mathrm{Mg} \mathrm{ha}{ }^{-1}\right)$. O experimento foi conduzido durante 65 dias.

Após o preenchimento dos 32 vasos com o solo e as doses de matéria orgânica (esterco de bovino) que foram previamente misturados, realizou-se a semeadura com o milho, utilizando-se o híbrido EXD710 YG, na proporção de cinco sementes por vaso. Após a emergência das plantas, efetuou-se o desbaste, restando apenas duas plantas em cada recipiente.

O experimento foi conduzido em casa de vegetação realizando-se diariamente a reposição de água no solo. Com 60 dias após a semeadura, foram feitas as avaliações da altura de planta, medindo com auxílio de uma régua, do solo até o ápice da última folha. Após 65 dias da semeadura realizou-se a coleta das plantas na qual, foram separados o sistema radicular da parte aérea e executada a limpeza das raízes para remoção do solo. Este procedimento foi realizado cuidadosamente para que não ocorresse perda significativa de raízes. Foram também realizadas as coletas de amostras de solo para avaliação da atividade microbiana por meio da técnica de produção de $\mathrm{CO}_{2}$ (respiração do solo). Para isso, utilizou-se a metodologia de captura do $\mathrm{CO}_{2}$ através de uma solução de $\mathrm{NaOH}(0,025 \mathrm{M})$ em frascos herméticos (ALEF; NANNIPIERI, 1995).

As plantas foram levadas para o laboratório e postas na estufa, de circulação forçada, ajustada para $60^{\circ} \mathrm{C}$ onde permaneceram por cinco dias para 0 procedimento de secagem. Após os cinco dias e obtenção de massa constante, foram realizadas as pesagens das raízes e partes aéreas.

Os dados foram avaliados por análise de regressão utilizando-se o programa estatístico Sisvar (Versão 5.6), com obtenção das curvas e estabelecimento de coeficiente $r^{2}$.

\section{RESULTADOS E DISCUSSÃO}

A aplicação de doses crescentes de esterco natural (sem irradiação) se ajustaram de forma linear crescente na avaliação da altura das plantas Figura 1. Isso não aconteceu quando foi utilizado o esterco irradiado. Nesse caso, ocorreu um ajuste exponencial com o ponto máximo próximo da dose de $10 \mathrm{Mg} \mathrm{ha}^{-1}$.

Figura 1. Análise de regressão de altura de milho aos 60 dias após a semeadura, cultivado em solo com diferentes doses de matéria orgânica, irradiada (sim) e não irradiada (não).

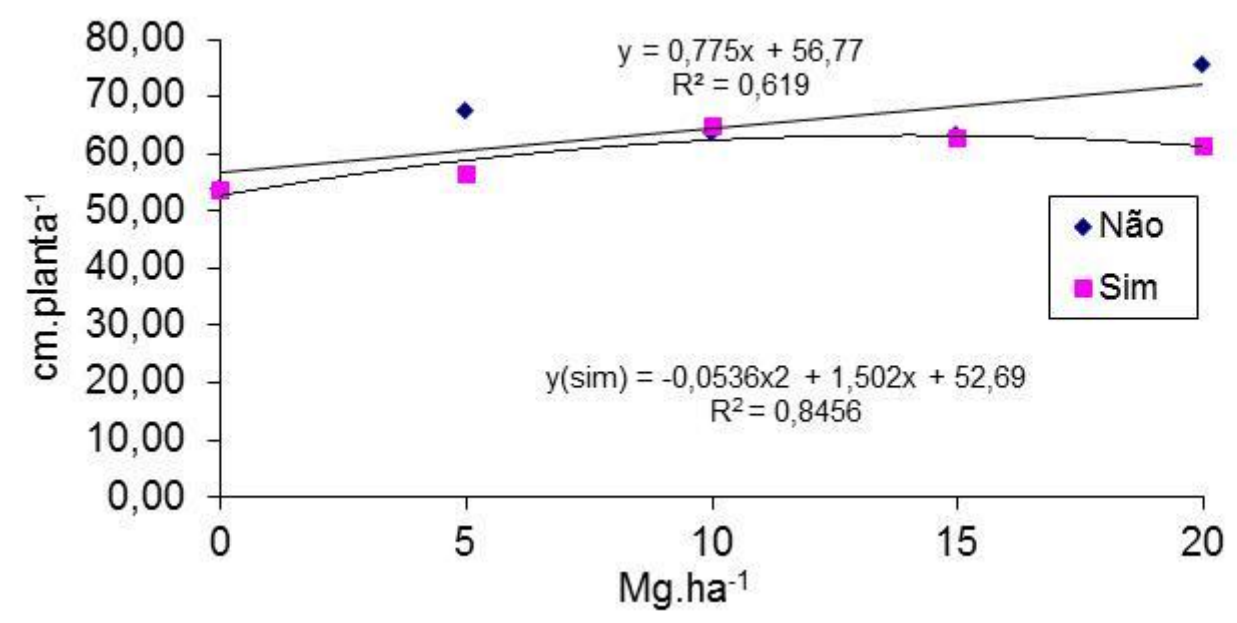


$\mathrm{Na}$ avaliação da respiração do solo Figura 2, pode-se observar que nas maiores doses de matéria orgânica natural, a respiração obteve um valor médio, acima de $1,0 \mathrm{mg}$ de $\mathrm{CO}_{2} \mathrm{~h}^{-1}$. Por outro lado, com o uso da matéria orgânica irradiada, os valores médios foram abaixo de $0,8 \mathrm{mg}$ de $\mathrm{CO}_{2} \mathrm{~h}^{-1}$, com ajuste linear crescente enquanto que, na aplicação do material não irradiado, o ajuste foi quadrático.

Figura 2. Análise de regressão da respiração do solo aos 60 dias de cultivo de milho com diferentes doses de matéria orgânica, irradiada (Sim) e não irradiada (Não).

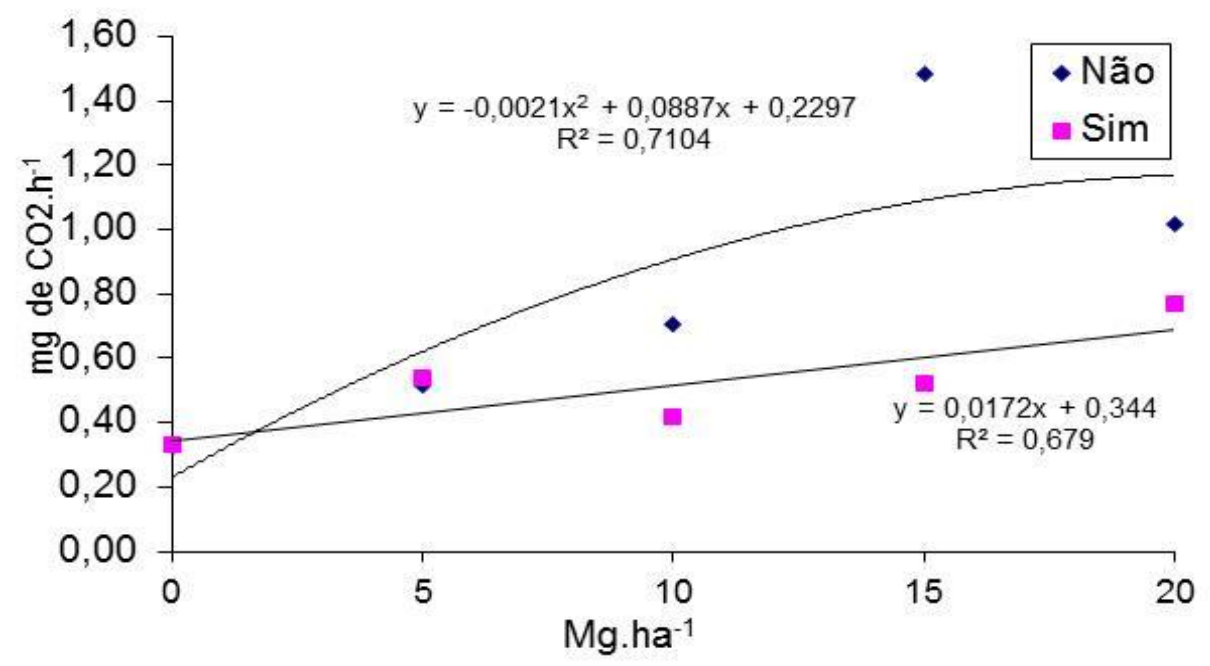

A dose próxima de 10 toneladas de esterco natural foi suficiente para promover o máximo enraizamento das plantas, de acordo com o ajuste quadrático apresentado na Figura 3. No uso do esterco irradiado o ajuste foi linear e o pico máximo de enraizamento ocorreu apenas na maior dose de $20 \mathrm{Mg} \mathrm{ha}^{-1}$.

Figura 3. Análise de regressão de massa seca (g) da raiz de milho aos 65 dias após a semeadura, cultivado em solo com diferentes doses de matéria orgânica, irradiada (Sim) e não irradiada (Não).

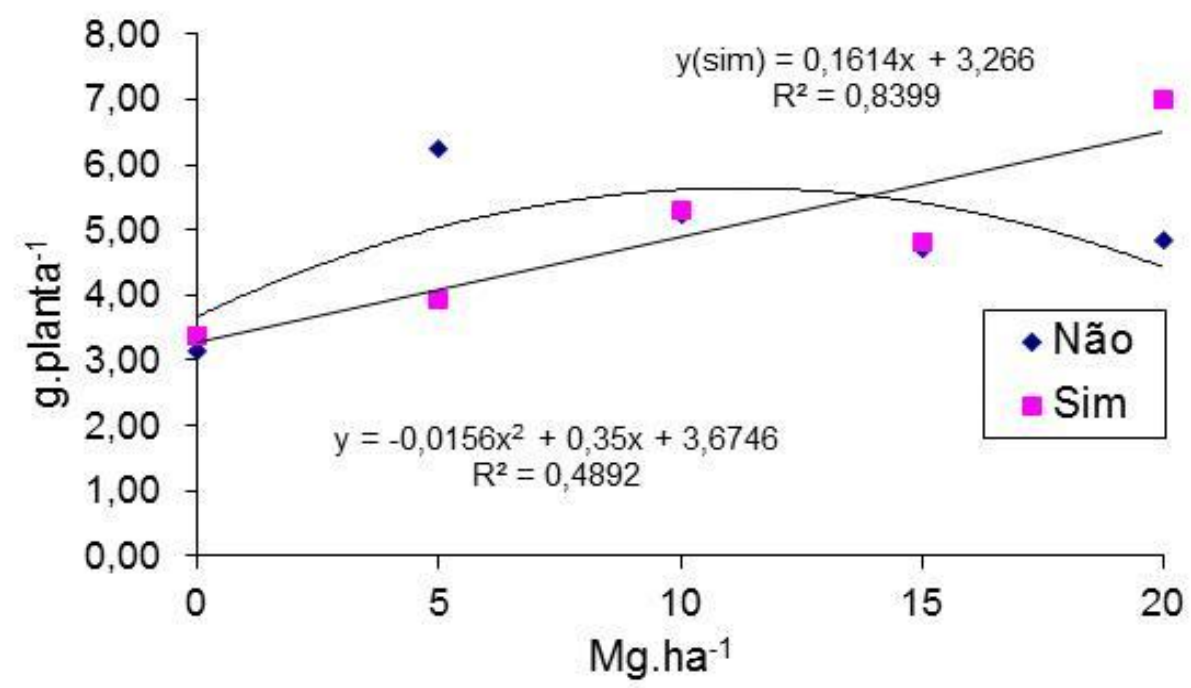

Semelhante ao encontrado no crescimento da parte aérea pode ser crescimento das raízes, na análise de observado que as doses próximas de 10 
toneladas por hectare de esterco natural promoveram o maior crescimento das plantas Figura 4. É possível notar que, o ajuste linear encontrado com o uso do esterco irradiado não gerou valores superiores ao encontrado com o esterco natural, em todas as doses analisadas.

Figura 4. Análise de regressão da massa seca da parte aérea (g) de milho aos 65 dias após a semeadura, cultivado em solo com diferentes doses de matéria orgânica, irradiada (Sim) e não irradiada (Não).

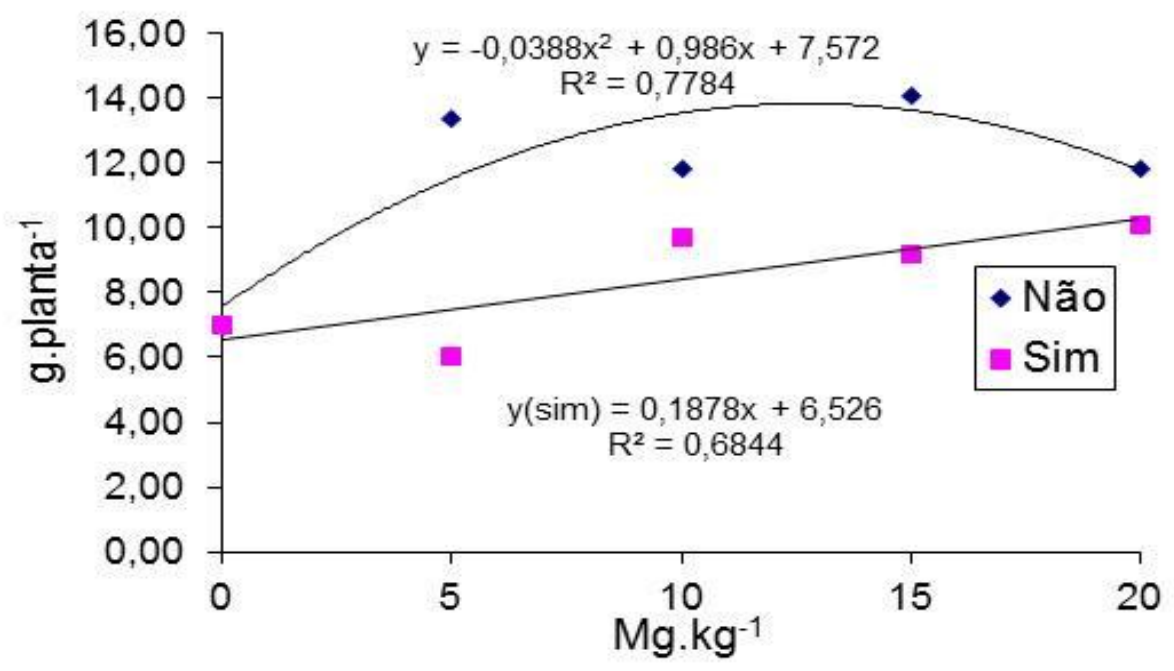

O uso de esterco natural na adubação orgânica em plantas de milho, com avaliação após 65 dias de cultivo proporcionou maior crescimento de parte aérea. O mesmo foi obtido por Guareschi et al. (2013), onde as plantas apresentaram resposta positiva até a dose máxima de 40 $\mathrm{mg} \mathrm{ha}^{-1}$ estudada. Do mesmo modo, Silva et al. (2004), estudando o efeito do esterco bovino em doses que variaram de 0 a $60 \mathrm{Mg}$ $\mathrm{ha}^{-1}$ na cultura do milho, perceberam que essas doses aumentaram linearmente a altura das plantas.

Em relação à respiração do solo, nesse estudo, o solo com a maior dose de matéria orgânica natural obteve um valor médio, acima de $1,0 \mathrm{mg}$ de $\mathrm{CO}_{2} \mathrm{~h}^{-1}$ quando comparado a matéria orgânica irradiada. Resultado similar foi encontrado por Feba et al. (2014), onde, elevadas doses de esterco natural gerou o aumento da respiração do solo, indicando que, conforme o teor de matéria orgânica fosse elevado, maior seria a presença de microrganismos presentes nesse solo.
De acordo com Slam e Weil (2000), a respiração basal expressa o estado em que se encontra o metabolismo microbiano no solo, retratando diretamente a decomposição de resíduos orgânicos, onde quanto maior a quantia de $\mathrm{CO}_{2}$ liberada para o ambiente, maior será a atividade microbiana. Desse modo, altas taxas de respiração podem indicar tanto uma condição adversa, como níveis adequados de atividade microbiana no solo.

As plantas de milho alcançaram o máximo enraizamento quando receberam 10 toneladas de esterco natural (10 $\left.\mathrm{t} \mathrm{ha} \mathrm{h}^{-1}\right)$. Conforme Feba et al. (2014) em seu trabalho, verificaram enraizamento significativo quando as dosagens do esterco foram próximas de $60 \mathrm{t} \mathrm{ha}^{-1}$. Salientando-se que esse esterco estava curtido com 90 dias de estocagem o que pode ter influenciado na composição microbiana do mesmo.

De acordo com os resultados encontrados a partir da utilização de matéria orgânica no solo, pode ser ressaltado que a presença dos microrganismos influenciou positivamente a atividade microbiana do solo 
medida pela respiração. As melhores respostas observadas no crescimento do milho foram encontradas nas menores doses de adubação orgânica, quando utilizou-se o esterco na forma natural e mais fresco. Estes fatos reforçam a importância dos microrganismos associados à presença de matéria orgânica no solo como forma mais eficiente de se utilizar a adubação orgânica.

\section{CONCLUSÕES}

- A aplicação do esterco natural favoreceu a maior atividade microbiana no solo quando comparada a mesma matéria orgânica esterilizada pela técnica de irradiação por micro-ondas.

- O esterco natural promoveu o maior crescimento do milho utilizando-se doses próximas de dez toneladas por hectare.

- O uso do esterco irradiado proporcionou ajustes lineares com resposta crescente positiva no crescimento do milho em resposta ao aumento das doses da adubação.

\section{REFERÊNCIAS}

ALEF, K.; NANNIPIERI, P. Methods in applied soil microbiology and biochemistry. London: Academic Press, 1995. p.576.

ARAÚJO, A. S. F.; CESARZ , S.; LEITE, L. F. C.; BORGES, C. D.; TSAI, S. M.; EISENHAUER, N. Soil microbial properties and temporal stability in degraded and restored lands of Northeast Brazil. Soil Biology e Biochemistry, v. 66, p. 175-181, 2013. https://doi.org/10.1016/i.soilbio.2013.07.013

BURNS, R. G.; DE FOREST, J. L.; MARXSEN, J.; SINSABAUGH, R. L.; STROMBERGER, M. E.; WALLENSTEIN, M. D.; WEINTRAUB, M. N.; ZOPPINI, A. Soil enzymes in a changing environment: current knowledge and future directions. Soil Biology and Biochemistry, v. 58, p. 216-234, 2013. https://doi.org/10.1016/j.soilbio.2012.11.009
BRUMMER, E.C. Diversity, stability and sustainable american agriculture. Agronomy Journal, v.90, n.1, p.1-2, 1998. https://doi.org/10.2134/agronj1998.0002196 $\underline{2009000010001 x}$

CASTRO, S. H.; REIS, R. P.; LIMA, A. L. R. Custos de produção da soja cultivada sob sistema de plantio direto: estudo de multicasos no oeste da Bahia. Ciência e Agrotecnologia, v. 30, n. 6, p. 1146-1153, 2006. https://doi.org/10.1590/S141370542006000600017

DOAN,T. T. et al. Impact of compost, vermicompost and biochar on soil fertility, maize yield and soil erosion in Northern Vietnam: A three year mesocosm experiment. Science of the Total Environment, Barcelona, v. 514, n. 1, p. 147154, 2015.

ERNANI, P.R. Necessidade de adição de nitrogênio para o milho em solo fertilizado com esterco de suínos, cama de aves e adubos minerais. Revista Brasileira de Ciência do Solo, v. 8, n. 3, p.313-317, 1984.

FEBA, L. T.; RAMPAZZO, C. S.; ARAUJO, F. F. Atividade microbiana e crescimento do milho em função de doses elevadas de esterco bovino no solo. Colloquium Agrariae, v. 10, n. Esp., p. 24-30, 2014.

GOULART, E.C. et al. Uso de cama de aves na adubação da cultura do milho. Centro Cientifico Conhecer, v.11, n.22, p. 27422748, 2015.

GRISI, B.M.; GRAY, T.R.G. Comparação dos métodos de fumigação, taxa de respiração em resposta à adição de glicose e conteúdo de ATP para estimar a biomassa microbiana do solo. Revista Brasileira Ciência do Solo, v. 10, p. 109-115, 1986.

GUARESCHI, R. F. et al. Adubação orgânica na produção de biomassa de milho em latossolo 
de cerrado. Global Science Technology, v. 6, n. 2, p. 66-73, 2013. https://doi.org/10.14688/1984-

\section{1.v06n02a08}

ISLAM, K. R.; WEIL, R. R. Land use effects on soil quality in a tropical forest ecosystem of Bangladesh. Agriculture Ecosystems and Environment, v. 79, n. 1, p. 9-16, 2000. https://doi.org/10.1016/S01678809(99)00145-0

MENESES, O.B. Efeitos de doses de esterco no rendimento do feijão-de-corda e do milho em cultivos isolados e consorciados. 1993. Dissertação (Mestrado) - ESAM, Mossoró, 1993.

MARROCOS, S. T. P. et al. Composição química e microbiológica de biofertilizantes em diferentes tempos de decomposição.

Revista Caatinga, v. 25, n. 4, p. 34-43, 2012.

PRAGANA, R. B.; NOBREGA, R. S. A.; RIBEIRO, M. R.; LUSTOSA FILHO, J. F. Atributos biológicos e dinâmica da matéria orgânica em latossolos amarelos na região do cerrado piauiense sob sistema plantio direto. Revista Brasileira de Ciência do Solo, v. 36, p. 851858, 2012. https://doi.org/10.1590/S0100$\underline{06832012000300015}$

SILVA, J. et al. Efeito de esterco bovino sobre os rendimentos de espigas verdes e de grãos de milho. Horticultura Brasileira, v. 22, n. 2, p. 326-331, 2004. https://doi.org/10.1590/S010205362004000200033

TEJADA, M. et al. Use of biofertilizers obtained from sewage sludges on maize yield. European Journal of Agronomy, v. 78, p. 13-19, 2016.

https://doi.org/10.1016/i.eja.2016.04.014
Recebido para publicação em 04/10/2018 Revisado em 05/01/2019 Aceito em 10/01/2019 